\title{
Intrapleural urokinase in the treatment of complicated parapneumonic pleural effusions and empyema
}

\author{
D. Bouros*+, S. Schiza*, N. Tzanakis ${ }^{++}$, J. Drositis**, N. Siafakas*++
}

\begin{abstract}
Intrapleural urokinase in the treatment of complicated parapneumonic pleural effusions and empyema. D. Bouros, S. Schiza, N. Tzanakis, J. Drositis, N. Siafakas. (C)ERS Journals Ltd 1996.

ABSTRACT: Intrapleural urokinase has not been evaluated systemically in terms of efficacy, safety, and cost of treatment in a large series of patients with complicated (parapneumonic) pleural effusions (CPE) and pleural empyemas (PE). Furthermore, the optimal dose and duration of treatment is not known.

Twenty consecutive patients with multiloculated parapneumonic effusions (13 with $\mathrm{CPE}$ and 7 with PE), in whom a single chest tube failed to drain the fluid, were studied prospectively. The age of the patients ranged 15-92 yrs (median 51 yrs). Urokinase was administered intrapleurally, in a low single daily dose of 50,000 $\mathrm{U}$ in $100 \mathrm{~mL}$ normal saline via the chest tube. Previous intrapleural instillation of $100 \mathrm{~mL}$ normal saline failed to promote drainage in all patients.

Urokinase enhanced drainage in all patients. Clinical and radiological improvement was noted in all but one patient. The mean (SD) volume of fluid significantly increased in the first $24 \mathrm{~h}$ post-urokinase $(\mathbf{p}<0.001)$. The number of urokinase instillations ranged 3-7 (median 5). Radiological evaluation showed excellent improvement in 13 of the $20(65 \%)$ patients. Urokinase was well-tolerated in all patients. The clinical course of patients was uneventful at a mean follow-up of $\mathbf{1 5}$ months (range 6-30 months) later. Mean total cost of treatment was $\$ 530 \pm 34.6$.

Our results show that intrapleural instillation of small doses of urokinase is a cost-effective and safe mode of treatment of complicated pleural effusions and pleural empyema and could be the fibrinolytic of choice.

Eur Respir J., 1996, 9, 1656-1659.
\end{abstract}

\author{
Depts of *Thoracic Medicine, **Thoracic \\ Surgery and +Clinical Pharmacology, Medi- \\ cal School, University of Crete, and ${ }^{++}$Uni- \\ versity General Hospital, Heraklion, Crete, \\ Greece. \\ Correspondence: D. Bouros \\ Dept of Thoracic Medicine \\ University General Hospital \\ Heraklion 71110 \\ Crete \\ Greece \\ Keywords: Empyema \\ fibrinolytics \\ pleural effusion complications \\ pleural empyema \\ respiratory infections \\ urokinase \\ Received: October 121995 \\ Accepted after revision March 291996 \\ Presented in part at the annual Congress \\ of the European Respiratory Society, \\ September 16-20, 1995, Barcelona, Spain.
}

The best methods for treating complicated parapneumonic pleural effusions (PPE) and pleural empyemas (PE) remain debatable [1-3]. In addition to antibiotic therapy, it is obligatory to secure adequate drainage to prevent the development of further complications [1, 4-7]. Although traditional (simple tube thoracostomy, rib resection, decortication and thoracoplasty) and newer (video-assisted thoracoscopy) surgical options are effective, any treatment that reduces the number of surgical interventions is preferred by patients and doctors [6].

Enzymatic debridement of the pleural cavity is an option that is frequently overlooked. This may be due to the fact that most of the reported series have included only a few patients or were case reports. Streptokinase is currently recommended as the fibrinolytic of choice [7-12].

In contrast to streptokinase, urokinase produces no antibody response, does not produce febrile reactions, and its efficacy is not inactivated by antibody production [13]. In a few small series, intrapleural administration of urokinase has been shown to be effective in PPE and PE [14-18]. However, its role in terms of efficacy and safety has not been studied systematically and the optimal dose and duration of treatment is not known.
We investigated the efficacy, safety and cost of intrapleural administration of small doses of urokinase, used as an adjunct to chest tube drainage in the management of complicated pleural effusions (CPE) and pleural empyema, in a large series of patients in whom initial single chest tube insertion failed to drain the effusion.

\section{Methods}

\section{Patients}

Between January 1990 and October 1994, 20 patients with complicated PPE (13 patients) and pleural empyema (7 patients) were admitted to our hospital. Parapneumonic effusion was defined as an effusion associated with bacterial pneumonia, lung abscess, or bronchiectasis [1-2]. Patients with complicated PPE had a multiloculated effusion confirmed by chest computed tomographic scanning (CT), ultrasound (US), or both, which did not resolve with a single tube thoracostomy. Patients with pleural empyema had pus on thoracentesis, or positive smear or pleural fluid cultures for bacteria and concomitant pneumonia, irrespective of the number of white blood cells in the pleural fluid $[1,2]$. 
All 20 consecutive patients were prospectively studied. Their age ranged 15-92 yrs (median 48 yrs), 14 males and 6 females. Inclusion criteria for the protocol were: multiloculated pleural effusion confirmed by chest CT and/or US; and failure of drainage via thoracostomy $(<70$ $\mathrm{mL}$ for the last $24 \mathrm{~h}$ ), after intrapleural instillation of $100 \mathrm{~mL}$ of normal saline and after assurance that tube clogging, kinking or improper positioning was excluded.

Multiloculations were defined as obvious septations seen on chest CT and/or US, or air-fluid levels in the pleura seen on chest radiography. Exclusion criteria were: the presence of florid sepsis; bronchopleural fistula; and contraindication to thrombolytic therapy, such as history of haemorrhagic stroke, intracranial neoplasm, cranial surgery or head trauma within 14 days, or major thoracic or abdominal surgery within 10 days.

Underlying diseases or predisposing factors for the development of pneumonic infection were: alcohol abuse (1); lung malignancy with postobstructive pneumonia (2); head injury with obtundation and aspiration (2); epilepsy with aspiration (1); subdiaphragmatic infection (1); diabetes mellitus (4); and periodontal disease (2). In the other seven patients, no predisposing factors or underlying diseases were identified. No patient had positive blood cultures for common pathogens. Sputum cultures were positive in three patients and pleural fluid cultures were positive in five, two of whom also had positive sputum cultures.

\section{Urokinase instillation}

Closed intercostal drainage was carried out with a 28 $32 \mathrm{~F}$ chest tube attached to a water-sealed system. Drainage from the chest tube was recorded every $8 \mathrm{~h}$. Urokinase was administered intrapleurally on a daily basis, as a solution of $50,000 \mathrm{U}$ in $100 \mathrm{~mL}$ of $0.9 \%$ saline solution via the chest tube using a syringe and a 21-gauge needle. The tube was subsequently clamped for $3 \mathrm{~h}$ and the patient was rotated in various positions to disperse the drug. Consequently, the chest tube was opened to suction. The interval time from the chest tube placement to initiation of urokinase administration ranged 1-5 days. Urokinase was reinstilled, if on repeat US examination persistent pleural effusion was found $24 \mathrm{~h}$ after the previous instillation. In order to avoid any volume effect due to instillation or to serve as a control, before starting urokinase we instilled intrapleurally $100 \mathrm{~mL}$ of normal saline. Streptokinase was instilled if the drained volume was not changed after $24 \mathrm{~h}$.

\section{Assessment}

The effectiveness of our protocol was assessed by: 1) clinical outcome (reduction in fever, pain, dyspnoea and cough, and improvement in general well-being); 2) monitoring the volume of fluid drained from the chest tube daily; 3 ) chest radiography; and 4) serial chest US and/or CT. An unfavourable response was defined by the following, despite good tube position: continued or worsening symptomatology; and no improvement or worsening in the imaging picture, manifested by increase in pleural fluid volume or appearance of new air-fluid levels. Decision to continue urokinase instillation or to proceed to open thoracotomy was taken by the attending pneumonologist and thoracic surgeon on the basic of clinical judgement. Chest tubes were removed after the net fluid drainage was less than $50 \mathrm{~mL}$ in $24 \mathrm{~h}$. Haematological studies included determination of haematocrit, platelet count, prothrombin time, activated partial thromboplastin time, and levels of fibrinogen.

Radiographic improvement was evaluated independently by two specialists, a pneumonologist and a radiologist. The last chest radiograph (CXR) prior to urokinase initiation and the CXR taken at the end of the urokinase administration were evaluated. The changes in chest radiography used for scoring were the reduction (improvement) in the dimensions of the pleural effusion at right angles to each other, as described previously [5]. Briefly, they were scored as: 0 (no change); 1 (less than $1 / 3$ improvement); 2 (improvement between $1 / 3$ to $2 / 3$ ); and 3 (more than $2 / 3$ improvement). If there was interobserver disagreement on scoring, the lower score was recorded. Serial US evaluation was made by an experienced operator for the presence of persistent loculations.

The volume of pleural fluid drained from the chest tube was recorded daily as well as the total solution instilled in the pleural cavity. Body temperature was recorded every $3 \mathrm{~h}$ and the maximum measurements prior and after urokinase administration were compared. The protocol had been reviewed and approved by the Ethics Committee of the institution.

\section{Pleural fluid data}

Pleural fluid analysis on initial thoracentesis showed an exudate pleural effusion in all patients according to the criteria of Light $[1,2]$. Macroscopically turbid fluid was found in all but seven patients, in whom it was purulent. Pleural fluid $\mathrm{pH}(\leq 7.2)$ and glucose $\left(\leq 60 \mathrm{mg} \cdot \mathrm{dL}^{-1}\right)$ were low in all patients. White blood cell count (WBC) was elevated in all 20 patients (mean $22.9 \times 10^{9}$ cells $\cdot \mathrm{L}^{-1}$ ).

\section{Follow-up}

All patients were followed up for a mean period of 10 months (range 7-24 months) by clinical examination, chest radiography, US and/or CT of the thorax.

\section{Statistical analysis}

All values are expressed as mean \pm sD. Comparison of means between groups was performed with the Chisquared test and two-way analysis of variance (ANOVA). A p-value of less than 0.05 was considered significant.

\section{Results}

Clinical improvement in terms of fever, dyspnoea, discomfort, debilitation, etc. was noted after the end of the course of urokinase in all but one patient (No. 5). This patient underwent thoracotomy 5 days post-urokinase due 


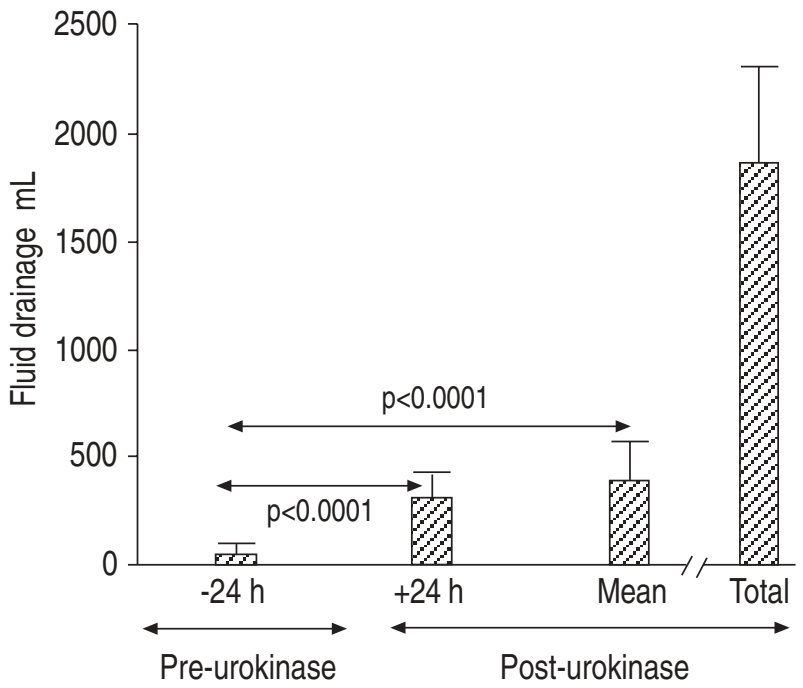

Fig. 1. - Fluid drainage before $(-24 \mathrm{~h})$ and after $(+24 \mathrm{~h}$, mean daily and total) urokinase treatment. The $24 \mathrm{~h}$ mean drained pleural fluid was significantly increased after urokinase treatment. Values are presented as mean \pm SD.

to unfavourable response (worsening symptomatology after initial improvement and apyrexia, minimal CXR improvement and persistent loculation on repeat US examination). On surgical exploration, a stage III pleural empyema (organizing stage) was found, and an empyematectomy was performed with a long-term successful result.

The total drainage before the use of urokinase ranged $50-540 \mathrm{~mL}$ over $2-6$ days. The mean $( \pm \mathrm{SD})$ volume of pleural fluid drained during the $24 \mathrm{~h}$ before urokinase instillation was $48 \pm 20 \mathrm{~mL}$ (range $0-70 \mathrm{~mL}$ ). No significant difference in the drained fluid was observed before and after normal saline instillation. The mean $( \pm \mathrm{SD})$ volume of pleural fluid drained during the first $24 \mathrm{~h}$ posturokinase was $310 \pm 96 \mathrm{~mL}$ (range $300-1,320 \mathrm{~mL}$ ), and the mean $( \pm \mathrm{SD})$ net total fluid drained $1,858 \pm 670 \mathrm{~mL}$ (range 590-2,600), (fig. 1). A significant increase of drained volume after urokinase instillation was observed at $24 \mathrm{~h}$ in comparison to pre-urokinase drainage $(\mathrm{p}<0.0001)$. The mean daily drainage with urokinase treatment was significantly greater in comparison with the last $24 \mathrm{~h}$ drainage prior to urokinase $(\mathrm{p}<0.0001)$ (fig. 1$)$. The number of urokinase instillations ranged 3-7 (median 5).

The overall CXR improvement score was $2.6 \pm 0.75$ as determined by both observers. A score of 3 improvement (excellent) on CXR was noted in 15 patients $(70 \%)$; a score of 2 (moderate) in two patients (15\%); and another three patients had a score of 1 (minimal improvement). The two patients with clinical but minimal CXR improvement at follow-up showed a progressively resolving pleural thickening. The third patient without clinical improvement underwent thoracotomy as mentioned above. The overall success rate for urokinase treatment was $95 \%$.

No significant changes in the coagulation profile of the patients were observed. All patients tolerated the drainage procedures and instillation of urokinase well. No adverse reactions or side-effects due to urokinase administration was noted. Pain during instillation occurred in one patient, but it was not severe enough to stop treatment. The 19 patients successfully treated with urokinase had no recurrences and were doing well at follow-up.
The total hospital stay after beginning urokinase fibrinolysis was $10.4 \pm 4.2$ (range 7-15) days. The cost per dose (50,000 IU) of urokinase (in USA \$) was \$106 and the mean total cost of a course of urokinase for 5 days (the mean number of treatment days of this series) was $\$ 530$. Given that the cost per dose (usual dose of 250,000 IU) of urokinase is $\$ 122$, the cost of urokinase is cheaper than streptokinase.

\section{Discussion}

Where as streptokinase has been reported to be effective and safe in patients with CPE and PE, urokinase has rarely been evaluated [14-18]. Urokinase is a direct plasminogen activator, which is not antigenic, and the rare reactions observed with it are probably related to contaminants (pyrogens) in the solution [18].

In 1989, Moulton et al. [14] first reported the application of urokinase in loculated pleural effusions. This technique was further used in other small series [15-19], but the best dose of urokinase, frequency of instillation, and time of initiation of treatment have not yet been adequately determined. The reported doses of urokinase instillations have ranged 80,000-450,000 U, whilst the duration of treatment has ranged 3-8 days [14-18]. Furthermore, instillations have been left in place $1-4 \mathrm{~h}$ each and have been repeated at 1-24 h intervals. Duration of treatment is determined mainly by the presence of residual fluid collection as measured by repeat CXR, US and/or CT.

In the present prospective series of 20 consecutive patients with parapneumonic loculated pleural effusions, urokinase was used at a low dose of 50,000 $\mathrm{U}$ in 100 $\mathrm{mL}$ normal saline and the total time of retaining the drug into the cavity was $3 \mathrm{~h}$. The reason for choosing such a protocol was to test whether low doses of urokinase are effective, to reduce possible adverse reactions to urokinase, and to keep the cost of treatment to a minimum. The good results of our study show that this dose and time of treatment are sufficient for fibrinolysis.

In order to avoid any volume effect due to instillation or to serve as a control, before starting urokinase, 100 $\mathrm{mL}$ of normal saline was instilled intrapleurally. No significant difference in the drained fluid was observed before and after normal saline instillation, whereas significantly increased drainage was noted after urokinase initiation $(\mathrm{p}<0.0001)$ (fig. 1$)$.

Although comparative studies for the best dose and duration of tube clamping are not available, our results show that the technique we followed is safe. Furthermore, the $3 \mathrm{~h}$ duration of intrapleural clamping used proved successful in terms of pleural cleaning.

In a comparative study between two fibrinolytic drugs, we found that urokinase is as effective as streptokinase but safer [20]. The results of the present study suggest that intrapleural administration of urokinase in patients with loculated CPE or PE is a safe and effective approach in promoting drainage. Its use should be started early, if after chest tube placement inadequate evacuation of pleural fluid is noted radiographically with no clinical improvement. Its use may decrease the need for surgical intervention, as well as multiple chest tube placement, which increases discomfort, complications and cost 
of treatment. Our results do not suggest regular monitoring with coagulation studies in patients without preexisting coagulation abnormalities.

Concerns about the cost of urokinase and the low incidence of side-effects with purified streptokinase are probably the reasons why urokinase is rarely used [17]. The daily cost of 50,000 IU urokinase varies in different countries, e.g. \$106 in USA and \$33 in Greece, and the average cost of the drug for 5 days (average number of treatment days for our series) was $\$ 530$ and $\$ 158$, respectively. This is about the same cost as for the use of streptokinase, taking into account that the dose of streptokinase usually instilled is $250,000 \mathrm{IU}$ at a cost of $\$ 122$. The results of our study, which show that a minimal dose of urokinase is effective for fibrinolysis, could recommend it as the procedure of choice in cases of loculated parapneumonic effusions.

\section{References}

1. Light RW. Pleural disease. Dis Mon 1992; 38: 261-331.

2. Light RW. Parapneumonic effusions and empyema. Clin Chest Med 1985; 6: 55-62.

3. Bartlett JG. Bacterial infections of the pleural space. Semin Respir Infect 1988; 3: 308-321.

4. Orringer MB. Thoracic empyema: back to basics. Chest 1988; 93: 901-902.

5. Bartlett JG, Finegold SM. Anaerobic infections of the lung and pleural space. Am Rev Respir Dis 1974; 110: 56-77.

6. Kaplan DK. Treatment of empyema thoracis. Thorax 1994; 49: 845-846.

7. Bouros D, Schiza S, Panagou P, et al. Role of streptokinase in the treatment of acute loculated parapneumonic pleural effusions and empyema. Thorax 1994; 49: 852-855.

8. Tillet WS, Sherry S. The effect in patients of streptococcal fibrinolysis (streptokinase) and streptococcal des- oxyribonuclease on fibrinous purulent and sanguinous pleural exudations. J Clin Invest 1949; 28: 173-190.

9. Bergh NP, Ekroth R, Larsson S, Nagy P. Intrapleural streptokinase in the treatment of hemothorax and empyema. Scand J Thorac Cardiovasc Surg 1977; 11: 265-268.

10. Henke CA, Leatherman JW. Intrapleurally administered streptokinase in the treatment of acute loculated nonpurulent parapneumonic effusions. Am Rev Respir Dis 1992; 145: 680-684.

11. Taylor RFH; Rubens MB, Pearson MC, Barnes NC. Intrapleural streptokinase in the management of empyema. Thorax 1994; 49: 856-859.

12. Sahn SA. Managment of complicated parapneumonic effusions. Am Rev Respir Dis 1993; 148: 813-817.

13. Spann JF, Sherry S, Rubin RN. Techniques of achieving pulmonary, peripheral and coronary thrombolysis. In: Hurst JW, Schlant RC, Rackley CE, Sonnenblick EH, Wenger NK, eds. The Heart. New York, McGraw Hill, 1990; pp. 2177-2184.

14. Moulton JS, Moore PT, Mencini RA. Treatment of loculated pleural effusions with transcatheter intracavitary urokinase. AJR 1989; 153: 941-945.

15. Lee KS, Im JG, Kim YH, et al. Treatment of thoracic multiloculated empyemas with intracavitary urokinase: a prospective study. Radiology 1991; 179: 771-775.

16. Couser JI, Berley J, Timm EG. Intrapleural urokinase for loculated effusions. Chest 1992; 101: 1467-1469.

17. Robinson LA, Moulton A, Flemming WH. Intrapleural fibrinolytic treatment of multiloculated thoracic empyemas. Ann Thorac Surg 1994; 57: 803-814.

18. Pollack JS, Passik CS. Intrapleural urokinase in the treatment of loculated pleural effusions. Chest 1994; 105: 868-873.

19. Lahora JM, Haaga JR, Stellato T, et al. Safety of intracavitary urokinase with percutaneous abscess drainage. AJR 1993; 160: 171-174.

20. Schiza S, Bouros D, Panagou P, et al. Intrapleural streptokinase $v s$ urokinase in the treatment of loculated parapneumonic effusions. Eur Respir J 1994; 7: 272s. 